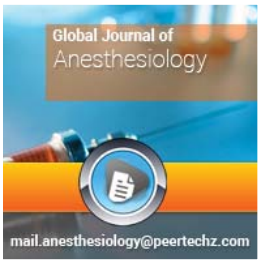

Medical Group

\title{
Global Journal of Anesthesiology
}

DOl:http://dx.doi.org/10.17352/gja

\section{Aravind kumar $\mathrm{E}^{1}$, Vinod} krishnagopal $^{2}$ and Krishna Prasad $\mathrm{T}^{3 *}$

'Post Graduate, Department of Anaesthesia, Shri Sathya Sai Medical College, Ammapettai, India ${ }^{2}$ Professor, Department of Anaesthesia, Shri Sathya Sai Medical College, Ammapettai, India

${ }^{3}$ Assistant professor, Department of Anaesthesia, Shri Sathya Sai Medical College, Ammapettai, India

Received: 14 March, 2019

Accepted: 28 March, 2019

Published: 29 March, 2019

*Corresponding author: Dr. Krishna Prasad T, Assistant Professor, Department of Anaesthesiology, 8A Staff Quarters, Sri Sathya Sai Medical College and Hospital, Ammapettai, 603108, India, Tel: 9944579455; E-mail: drkrishna86@gmail.com

Keywords: Adequacy; Combined lumbar sacral plexus block; Spinal; Epidural

https://www.peertechz.com

Check for updates
Research Article

A comparative study of three different anaesthetic techniques in unilateral elective hip surgeries (combined lumbosacral plexus block, spinal and epidural) - A prospective randomized single blinded study

\section{Abstract}

Background: To compare the Adequacy of combined lumbosacral plexus block over subarachnoid block and epidural in terms of motor blockade and sensory blockade, surgeon and patient satisfaction and time for first rescue analgesia for unilateral elective hip surgeries.

Materials and methods:A single centred randomized, single blinded study, conducted between May2017 to October 2018, on 60 patients undergoing elective unilateral hip surgeries with 20 patients in each group (group I -combined lumbar and sacral plexus block, Group II - Epidural \& Group IIISubarachnoid block). Patients belonging to American society of anaesthesiologists, physical status 1 \& 2 , aged between $18-60$ years were enrolled for the study and distributed randomly into one of the three groups. Adequacy of block in terms of motor and sensory blockade, patient and surgeon satisfaction and time for first analgesia were noted.

Results:Among 60 patients, block was adequate in group III, compared to group II and group I. The total duration of analgesia was significantly higher in group I (338.5 \pm 44.51$)$, compared to group II (135.5 $\pm 11.45)$ and GROUP III $(141.0 \pm 17.44)$. The total doses of analgesic required in the first 24 hours were low in group I, when compared to group II and group III.

Conclusion:Combined lumbosacral plexus block, is a good and safe alternative to neuraxial block for patients undergoing unilateral hip surgeries, with good patient and surgeon satisfaction and prolonged postoperative pain relief.

\section{Abbreviations}

SBP: Systolic Blood Pressure; DBP: Diastolic Blood Pressure; MAP: Mean Arterial Blood Pressure; HR: Heart Rate; PSIS: Posterior Superior Iliac Sspine; ASA; American Society of Anaesthesiologists; PFN: Proximal Femur Nailing: Sig: Significance; LSP: Lumbar and Sacral Plexus

\section{Introduction}

Patients presenting with hip fractures are more prone for morbidity and mortality. In 2050, it has been estimated that approximately more than fifty percentage of the population with hip fractures will occur in the Asian subcontinent [1].
In many countries, the fracture of the hip has become a global trend due to the expectancy of increased survival rate among population. This is due to the fact that the people at risk for fractures are more in the elderly group at risk of accidental falls .Furthermore, for every male with a fractured hip there are four women presenting with the same ailment on account of hormonal imbalance and osteoporosis [2].

Cost of hip fracture surgeries is a major burden to health care system. Patients presenting with hip fracture suffer from high rate of mortality, medical expenses, limitations of movement, decrease in quality of life, restriction fromWork and indirect factors associated with persons in the family who are responsible for the Welfare of the patient [3]. 
Surgical intervention is required to be done within 48-72hrs after admission either with General anaesthesia or regional anaesthesia to allow early ambulation, reduce mortality and reduce postoperative morbidity such as pneumonia and pressure ulcer [4]. These group of Patients are prone for complications because of concomitant drug administration like Antiplatelet / anticoagulants and coexisting illness like diabetic neuropathy and uncontrolled Hypertension. Selection of safe and optimal anaesthesia taking for the fore mentioned Complications is a challenge [5].

In general anaesthesia gaseous or intravenous drugs administered achieve anaesthesia by Central neurological depression. General anaesthesia provides better hemodynamic parameters,when compared with regional anaesthesia. General anaesthesia administered to these patients, has higher incidence of postoperative cognitive dysfunction, nausea and vomiting with increase in intragastric pressure, pulmonary complications and delay in recovery [6].

Regional anaesthesia offers safe and effective alternate to general anaesthesia. Regional anaesthesia for hip surgeries include central neuraxial blockade and peripheral plexus block. Regional techniques for lower limb surgeries relies on the drugs administered either into the epidural space or in the subarachnoid space [7].

Central neuraxial blockade may improve outcomes by significantly reducing the blood loss, avoidance of intubation and mechanical ventilation and improve postoperative analgesia and very low incidence with conditions such as deep vein thrombosis.

In spite of being simple to perform and rapid in onset, subarachnoid block is associated with its side effects like hypotension, single shot method, post dural puncture headache, urinary retention, back ache, nerve injury and cauda equine syndrome [8].

Though Epidural anaesthesia is associated with significantly less hypotension and absence of postdural puncture head ache it has shortcomings like segmental blockade, difficulty in placing the catheter, epidural hematoma. In addition, unilateral block can occur, if medication delivered through a catheter that has coursed laterally. Segmental sparring can occur due to septations, within the epidural space. Catheters can migrate intrathecally resulting in total spinal and intravascularly resulting in systemic complications [9].

Peripheral nerve blocks like psoas compartment block along with sacral plexus block can provide better and safe hemodynamics, minimal complications and faster recovery .It can be considered a safer alternative compared to general anaesthesia and central neuraxial block for unilateral hip surgeries [10].

Studies based on regional techniques, such as epidural and spinal anaesthesia, had more literature regarding fatal incidents. To provide more reliable and safer effects of neuraxial blockade, the adequacy of blockade, and time for first rescue analgesic, we conducted this study to assess the outcomes.
Combined lumbar and sacral plexus block has found to be effective compared to complications arising out of neuraxial anaesthesia. Therefore this study aims to report the outcome after using combined lumbar sacral plexus block in comparison with epidural and subarachnoid block, its effectiveness, safety and complication related to the procedure.

\section{Methodology}

This was a randomized single blinded study in patients undergoing unilateral elective hip surgeries most of which includes hemiarthroplasty and femoral nailing with prior approval from institutional ethical committee. Randomization was done according to computer generated numbers. Block would be administered by the same anaesthesiologist to avoid inter administrator basis. The outcomes would be assessed by another anaesthesiologist. The study was carried out during the period of May 2017 to October 2018.

In a study population of 60 patients undergoing unilateral elective hip surgeries between the age of 18 to 6oyears of both genders belonging to ASA physical status 1 and 2 were divided into three groups (Group I-combined lumbar and sacral plexus block, Group II - Epidural anaesthesia, Group III - Subarachnoid block). The study design was a Prospective randomized single blinded study done in unilateral elective hip surgeries, convenient sampling.

Patients were excluded in the presence of comorbidities like uncontrolled hypertension and diabetes, end stage renal and hepatic disease, coagulopathy, progressive neurological disorder, belonging to ASA grade III and above psychiatric illness.

After obtaining the informed written consent, the patient belonging to group ASA I/II undergoing elective hip surgeries was enrolled for the study. The surgery was performed by the same surgeon as the surgeon's satisfaction was studied. The outcome was assessed by another anaesthesiologist who is not aware of the procedure.

The patients were fasted 6 hours prior to anaesthesia. Intravenous access with $18 \mathrm{G}$ cannula was obtained. Monitoring of ECG, Spo2 and NIBP was done. Each patient was given glycopyrrolate $0.2 \mathrm{mg}$ iv, fentanyl 2microgram $/ \mathrm{kg}$ and midazolam $0.02 \mathrm{mg} / \mathrm{kg}$ iv before the procedure.

For patients belonging to group I, Patients were placed in lateral position with the side to be blocked as the nondominant side. A line was drawn connecting highest point of iliac crests (intercristal line, corresponding to L4spine). Two parallel Horizontal lines were drawn passing through spinous process and posterior superior iliac spine PSIS, intersecting the intercristal line. Needle insertion site is the junction of lateral third and medial two thirds of the line between the spinous process of L4 and the line passing through PSIS. The needle was advanced( nerve locater needle $15 \mathrm{~cm}$ current $1.5 \mathrm{~mA}, 2 \mathrm{hz}$ ) until it reaches transverse process of $\mathrm{L} 4$, then the needle is slightly withdrawn and directed caudal. Quadriceps contraction obtained with a current strength of $0.5-0.3 \mathrm{~mA}$ was the desired 
response. Local anaesthetic, $20 \mathrm{ml}$ of bupivacaine $0.25 \%$ was injected incrementally after repeated aspiration (Figure 1).

Sacral plexus block was carried out by placing the patient in the same position as mentioned above. A line was drawn connecting PSIS and ischial tuberosity. Along the line, a mark was made at $6 \mathrm{~cm}$ inferior to PSIS, defining the needle insertion point. The nerve stimulator needle $(15 \mathrm{~cm}, 1.5 \mathrm{~mA}, 2 \mathrm{~Hz})$ was advanced in a saggital plane until an evoked response was obtained (plantar or dorsiflexion, hamstring contraction) with a current of 0.3-0.5 MA. Local anaesthetic bupivacaine $0.25 \%$ $20 \mathrm{ml}$ was injected incrementally after repeated aspiration. Subcostal nerve was blocked by infiltration over the iliac crest with $5 \mathrm{ml}$ of $0.25 \%$ bupivacaine (Figure 2,3 ).

For patients in group II, epidural anaesthesia was given in sitting position. After sterile preparations, 18G epidural needle was inserted after local infiltration along the midline at the level of L2-L3. Epidural space was identified with loss of resistance technique and catheter was advanced and placed $5 \mathrm{~cm}$ in the epidural space.

Test dose: $3 \mathrm{ml}$ of $1.5 \%$ lignocaine with $5 \mathrm{mcg}$ of adrenaline per $\mathrm{ml}$ was administered. The patient was monitored for signs of intrathecal and intravascular placement of the catheter.

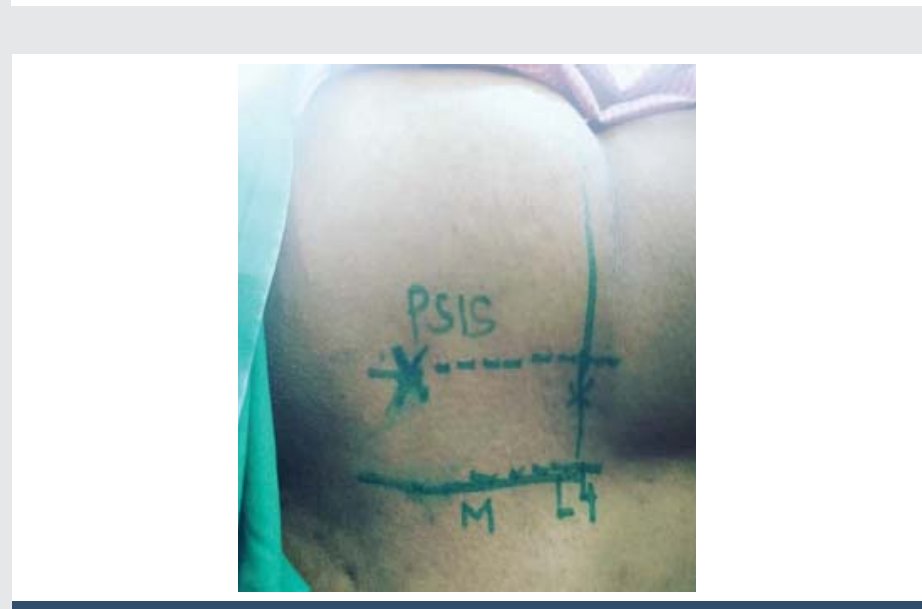

Figure 1: landmark for psoas compartment block.

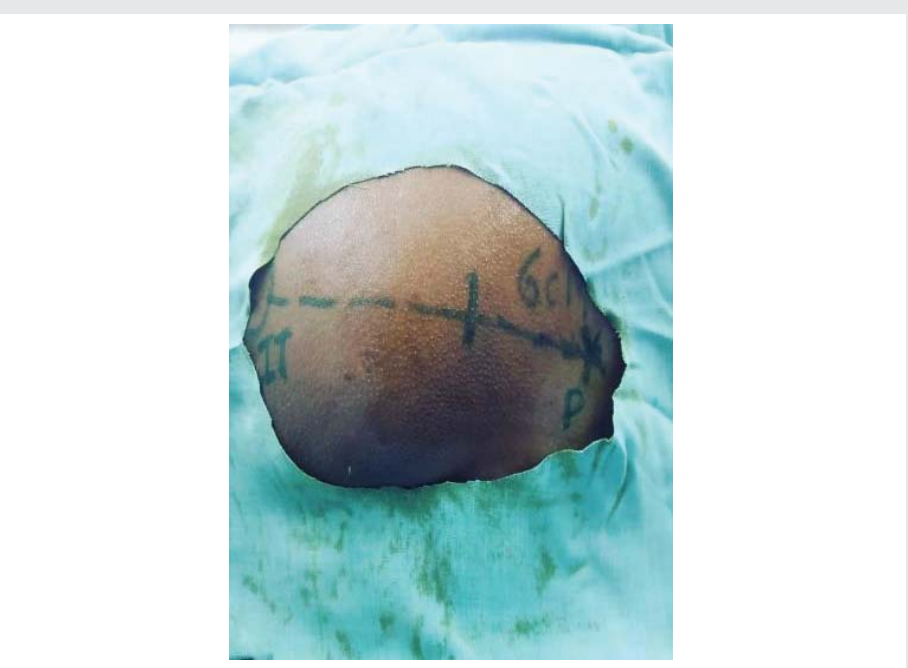

Figure 2: Landmark for sacral plexus block

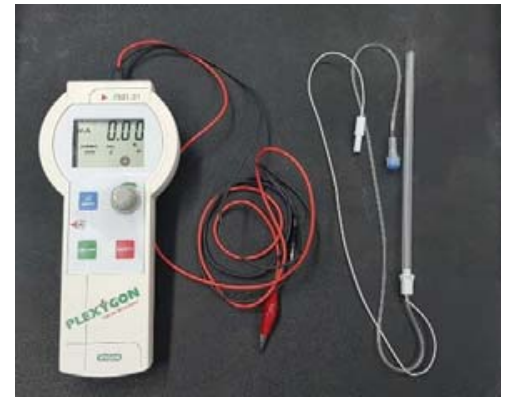

Figure 3: Nerve stimulator used for the procedure.

$12 \mathrm{ml}$ of $0.5 \%$ bupivacaine was administered after confirmation of the position of the catheter.

For patients undergoing procedure in group III, subarachnoid block was given. After placing the patient in the sitting position, under sterile aseptic preparations, 26G spinal needle was inserted after local infiltration along the midline at the level of L3-L4 spine. After confirmation of adequate flow of cerebrospinal fluid, $3.5 \mathrm{ml}$ of hyperbaric bupivacaine was administered in subarachnoid space. Onset of the block was assessed for every 5 minutes up till 40 minutes. In case of inadequate blockade patient was given general anaesthesia.

The outcomes assessed were adequacy for motor (Bromage scale) [9], \&sensory blockade (1- presence of sensation in one or more nerve distribution, 0 -absence of sensation), time for first analgesic (in minutes),patient and surgeon satisfaction using a two point scale ( 1 -satisfactory -if required i would like to have the same anaesthesia again(2-unsatisfactory-i would prefer a different type of anaesthesia)

Adequacy of Motor blockade- using Bromage scale ${ }^{9}$ (0 -No block $0 \%$-full flexion of knees \& feet possible, 1-partial 33\%just able to flex knee, full flexion possible in feet, 2-almost complete-66\%-unable to flex knee, flexion of feet possible, 3-complete-100\%-unable to flex knee and feet and (II) Sensory evaluation is carried out by a blunt 21-guage needle. Pin prick sensation would be assessed in1) sole of the foot (sciatic nerve) 2) anterior thigh (femoral nerve) 3) lateral thigh (lateral cutaneous nerve of thigh) 4) medial thigh (obturator nerve).

Time for first analgesic- measured in minutes from the time block was given to the time of demand of first analgesic by the patient. The patients were administered $2 \mathrm{mg} / \mathrm{kg}$ tramadol intramuscularly for analgesia.

\section{Results}

The results of this study have been expressed in the following headings:

\section{Age}

In our study population, among three groups, the mean age for the patients were studied. The mean age for the patients in group I was 50.05 years with standard deviation of 5.844, and I group II was 52.70 years with standard deviation of 6.432 and in group III was 52.95 with 6.816 . The $p$ value was 
0.289 (significant). The mean age with standard deviation and the $\mathrm{p}$ value are depicted in table 1 . Age distribution of patients is depicted in graph 1.

\section{Distribution of sex}

The distribution of sex among three groups in our study population were studied .Majority of population in our study were found to be in the age group of 56-60 which constituted $36.7 \%$, in the age group of $51-55$ it was $25 \%$ and in the age group of 46-50 it was $21 \%$ and $16.7 \%$ in the age group of 45. The distribution of sex among the age category in three different groups is depicted in table 2 .

\section{Groups}

In our study group, which had a population of 60 patients, patients were divided into three groups, with 20 persons in each group (combined Lumbar and Sacral Plexus, Epidural and Spinal). The distributions of patients in these three groups are depicted in graph 2 .

\section{Adequacy}

The block was adequate in group I, in 18 patients $(90 \%$, Bromage - motor 3, sensory1), and unsuccessful in 2 patients ( $10 \%$, Bromage - motor 0, sensory 0), who were Converted

Table 1: mean age of the patients in all three groups

\begin{tabular}{|c|c|c|c|}
\hline & Frequency & Mean age+/- SD & \\
\hline 1 & 20 & $50.0500+/-5.84425$ & $\begin{array}{c}\text { Sig. (p-value) } \\
.289\end{array}$ \\
\hline 2 & 20 & $52.7000+/-6.43265$ & \\
\hline 3 & 20 & $52.9500+/-6.81697$ & \\
\hline Overall & 60 & $51.9000+/-6.40630$ & \\
\hline
\end{tabular}

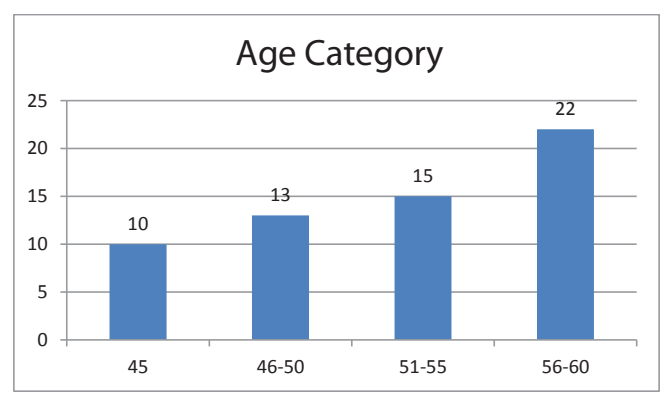

Graph 1: Age distribution of the patients.

Table 2: Distribution of sex.

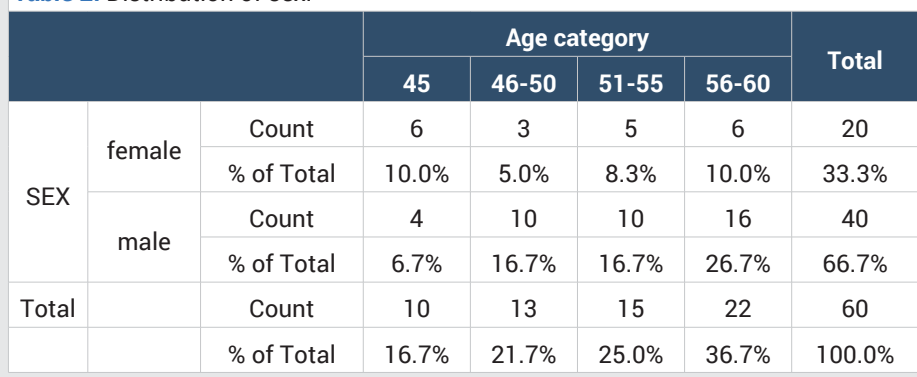

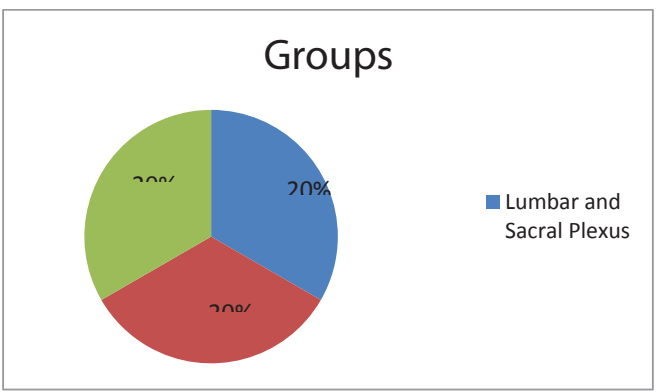

Graph 2: Distribution of group in patients undergoing procedure.

to General anaesthesia. In patients in group II, block was adequate in 17 patients ( $85 \%$, Bromage- motor 3 , sensory 1 ) and inadequate in 3 patients $(15 \%$, Bromage - motor -0 , sensory $-0)$. In patients belonging to group III, block was adequate in 19 patients (95\%, Bromage 3, sensory 1) and inadequate in 1 patient ( $5 \%$, Bromage - motor 0 , sensory 0 ). The chi-square

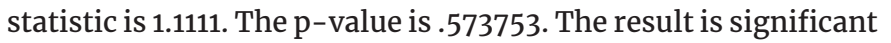
at $\mathrm{p}<0.05$. The adequacy of block is depicted in table 3 .

\section{Surgeon and patient satisfaction}

Among patients in group $\mathrm{I}$, the surgeon and Patient satisfaction was satisfactory in $90 \%$ and unsatisfactory in remaining $10 \%$. In group II, the surgeon and satisfaction was satisfactory in $85 \%$ and unsatisfactory in the remaining $15 \%$. And in group III, the percentage was $95 \%$ and $5 \%$ respectively (Table 4).

The chi-square statistic is 1.1111 . The $\mathrm{p}$-value is .573753 . The result is significant at $\mathrm{p}<0.05$.

\section{Time for analgesia}

The time for first analgesic was significant high in group 1 (combined lumbosacral plexus block) which was $338.5 \pm 44.51$, compared to group II (epidural) which was $135.5 \pm 11.45$ and group III (spinal) which was $141 \pm 17$.44.Independent $t$ was used to compare the means of the different groups and the time of analgesia is significantly different among each other with $\mathrm{p}$-value of $<0.001$. The results for the time for analgesia is depicted in table 5 .

\section{Discussion}

Peripheral plexus blocks, provides adequate and prolonged analgesia compared to other regional techniques. Plexus block has its advantage over general anaesthesia in avoiding complications like incidence of postoperative cognitive dysfunction, nausea and vomiting with increase in intragastric pressure, pulmonary complications and delay in recovery.

Hemodynamic parameters were better maintained in the plexus group while compared to the other regional techniques. Complications such as epidural hematoma, dural puncture and urinary retention were avoided in the plexus group.

The mean Age of the study population is 51.90 with a standard deviation of 7.68. Minimum age in the study was 38 and maximum age was 60 . Majority of the study population 
Table 3: Block adequacy

\begin{tabular}{|l|c|c|c|c|}
\hline & $\begin{array}{c}\text { Yes } \\
\text { BROMAGE MOTOR 3 } \\
\text { SENSORY 0 }\end{array}$ & $\begin{array}{c}\text { No } \\
\text { BROMAGE } \\
\text { MOTOR 0 } \\
\text { SENSORY 1 }\end{array}$ & Row Totals & Success rate \\
\hline Group 1 & 18 & $2 \times$ & 20 & $90 \%$ \\
\hline Group 2 & 17 & 3 & 20 & $85 \%$ \\
\hline Group 3 & 19 & 1 & 20 & $95 \%$ \\
\hline
\end{tabular}

Table 4: Surgeon and patient satisfaction.

\begin{tabular}{|c|c|c|c|c|}
\hline & $\begin{array}{c}\text { SURGEON \&PATIENT } \\
\text { SATISFACTION } \\
(\mathbf{1})\end{array}$ & $\begin{array}{c}\text { SURGEON AND PATIENT } \\
\text { SATISFACTION } \\
\mathbf{( 2 )}\end{array}$ & Row & Success \\
\hline Group 1 & 18 & 2 & 20 & $90 \%$ \\
\hline Group 2 & 17 & 3 & 20 & $85 \%$ \\
\hline Group 3 & 19 & 1 & 20 & $95 \%$ \\
\hline
\end{tabular}

Table 5: Time of analgesia

\begin{tabular}{|c|c|c|c|c|c|c|c|}
\hline & Frequency & Mean & $\begin{array}{c}\text { Std. } \\
\text { Deviation }\end{array}$ & Std. Error & Minimum & Maximum & p-value \\
\hline 1 & 20 & 338.5000 & 44.51789 & 9.95450 & 280.00 & 420.00 & $<0.001$ \\
\hline 2 & 20 & 135.5000 & 11.45931 & 2.56238 & 120.00 & 150.00 & \\
\hline 3 & 20 & 141.0000 & 17.44163 & 3.90007 & 100.00 & 170.00 & \\
\hline Total & 60 & 205.0000 & 99.22582 & 12.81000 & 100.00 & 420.00 & \\
\hline
\end{tabular}

were belonging to the 50-59 age categories. Majority of the study population were males, $40(66.7 \%)$. Each group in Lumbar and Sacral Plexus, Epidural and Spinal anaesthesia 20 subjects were studied.

So a total of 60 subjects have been studied.28 (47\%) were undergoing surgery in left femur and rest were undergoing surgery in right femur. Majority of study population were undergoing PFN surgery - $40(66.7 \%)$

The adequacy of block was more in spinal, followed by combined lumbar/ sacral plexus Block and epidural, but the difference was not statistically significant.

Chayen et al had a success rate of $90 \%$ in plexus blocks, while our study had a success rate with combined lumbar sacral plexus block with $90 \%$ which was comparable [11].

Parkinson et al conducted a study on Psoas compartment block, he used the technique of Dekrey's approach, which was approached at the level of L3, and L4-L5 level and had a Success rate of $96 \%$ and $91 \%$ which was comparable with our study [12]. In the study conducted by horsanli et al, patients who underwent psoas compartment Block, through the approach of capdevila s approach with $30 \mathrm{ml}$ of $0.375 \%$ ropivacaine and Sciatic (labatz technique), with $20 \mathrm{ml}$ of $0.375 \%$ ropivacaine, the success rate was $92.5 \%$, this was close to that of our study [13].

A clinical study performed by petchara et al, 70 patients who underwent PCB With $20 \mathrm{ml}$ of $0.5 \%$ levobupivacaine with $2 \%$ lignocaine with adrenaline in a 1:1 ratio and sciaitc block with transgluteal approach with $20 \mathrm{ml}$ of $0.5 \%$ levobupivacaine with $2 \%$ Lignocaine with adrenaline, surgical anaesthesia had a success rate of $100 \% .{ }^{14}$. In the study conducted by krishnagopal vinod et al, with patients undergoing PCB (capdevilla $\mathrm{s}$ approach) with $20 \mathrm{ml}$ of $0.25 \%$ bupivacaine and sciatic block with $20 \mathrm{ml}$ of $0.25 \%$ bupivacaine, the adequacy of combined lumbosacral plexus block was $93 \%$. The difference in patient and surgeon satisfaction among the three groups were not statistically significant [5].

In study conducted by horsanli et al, patient and surgeon satisfaction in lumbosacral plexus Group was 75.7 and $81 \%$ respectively.in the same study patient and surgeon satisfaction in Epidural group was 78.4 and $66.6 \%$. In our study patient and surgeon satisfaction was comparatively higher in all the three groups probably because of the premedication (fentanyl and midazolam) administered in our study [13].

In the study conducted by krishnagopal vinod et al, the overall patient and surgeon Satisfaction were 96.8 and 95.7 in our study the surgeon and patient satisfaction in the combined plexus block was $90 \%$ and this difference compared to the previous study could be Due to administration of intravenous dexmedetomidine [5].

The mean time for analgesia in our study was more in combine lumbosacral Plexus group (338.5 min), compared to epidural (135.5 min) and spinal Group (141.0min)

In a study conducted by Horsanli et al, with ropivacaine, the time for first rescue analgesic. In lumbo sacral plexus group was $360 \mathrm{~min}$, probably because of the use of ropivacaine in this study [13].

In a study conducted by Greengrass et al, the time for first rescue analgesic was $17 \pm 3$ hours. In a study conducted by vinod et al, the time for first analgesic was 347.69 minutes, which was comparable to our study .This difference is statistically significant with $\mathrm{p}$-value. Of $<0.001$ using one way ANOVA [15].

Based on the outcomes of our study, peripheral nerve plexus blocks like combined lumbosacral plexus block was found to have better hemodynamic stability and reduced requirement of postoperative analgesics, without any associated major complications .These studies were compared with neuraxial anaesthesia, which had less hemodynamic stability when compared with plexus blocks. Complications such as Nerve injury and contralateral spread was also studied [16].

Recent Advanced techniques for nerve localization with ultrasound guided imaging and techniques with the use of continuous catheter drug delivery have increased the incidence for performing plexus blocks for lower limb surgery. ${ }^{38}$ The regional anaesthesia techniques decrease neuroendocrine stress responses, central sensitization of the nervous system, and muscle spasms which occur in response to pain stimuli [17].

\section{Limitation}

1. Only the parameters related to adequacy of the block were studied in this study. The complications followed by the 
surgery, adverse events during the surgery, overall mortality were not studied.

2. Hip fractures are more common in geriatric population, which was not included in the study

3. Recent advances, like ultrasound guided blocks are proven to be beneficial, which was not included in the study.

4. Factors such as the perioperative bleeding, operative time were not studied.

\section{Conclusion}

The Adequacy, in terms of motor and sensory block, patient \&surgeon satisfaction were similar in all the three groups. When compared in terms of hemodynamic stability \& post- operative analgesia, lumbosacral plexus block was more superior, than spinal and epidural. Hence we conclude that lumbosacral plexus block is an able and efficient alternative to subarachnoid block and epidural for hip surgeries.

\section{Acknowledgement}

Acknowledgement and celebration are essential to fueling passion, making people feel valid and valuable, and giving them a real sense of progress that makes it all worthwhile. It gives me immense pleasure for me to thank everyone who has helped me during the course of my study and in preparing this original article. I would like to express sincere thanks and profound gratitude to Chancellor and Vice Chancellor for granting me permission to carry out this study. I take this opportunity to convey my heartiest gratitude and sincere thanks to Dr. Krishnamoorthy S.N, M.D, Dr .Vinod Krishnagopal. P, M.D, and Dr. Krishna prasad. T, M.D.

\section{References}

1. Yoon HK, Park C, Jang S, Jang S, Lee YK, Ha YC (2011) Incidence and mortality following hip fracture in Korea. Journal of Korean medical science 26: 1087 1092. Link: https://goo.gl/oMhLRj

2. Rashid RH, Shah AA, Shakoor A, Noordin S (2013) Hip fracture surgery: does type of anesthesiamatter? BioMed research international. Link: https://goo.gl/PjLWam

3. Youm T, Koval KJ, Zuckerman JD (1999) The economic impact of geriatric hip fractures. Americanjournal of orthopedics (Belle Mead NJ) 28: 423-428. Link: https://goo.gl/vdnUd8
4. Beaupre LA, Jones CA, Saunders LD, Johnston DW, Buckingham J, et al (2005) Best practices for elderly hip fracture patients. Journal of general internal medicine 20: 1019-1025. Link: https://goo.gl/11 grkB

5. Vinod K, Kuhrekar P, Sharanya K (2017) Study on evaluating the Adequacy of Psoas Compartment block and sacral plexus block for lower limb surgeries. J Recent Adv Pain 3: 66-70. Link: https://goo.gl/MJxkCd

6. Kotekar N, Shenkar A, Nagaraj R (2018) Postoperative cognitive dysfunctioncurrent preventive strategies. Clinical interventions in aging 13: 2267-2273. Link: https://goo.gl/PKgoq

7. Rodgers A, Walker N, Schug S, McKee A, et al. (2000) Reduction of postoperative mortality and morbidity with epidural or spinal anaesthesia: results from overview of randomised trials 321: 1493. Link: https://goo.gl/zRTpkA

8. Guay J, Parker MJ, Gajendragadkar PR, Kopp S (2016) Anaesthesia for hip fracture surgery in adults. Cochrane Database of Systematic Reviews. Link: https://goo.gl/ZqTi5K

9. Bromage PR (1978) Epidural analgesia. WB Saunders Company

10. Farny J, Girard M, Drolet P (1976) Posterior approach to the lumbar plexus combined with a sciatic nerve block using lidocaine. Canadian journal of anaesthesia 4: 486. Link: https://goo.gl/1aDktS

11. Chayen D (1976) The psoas compartment block. Anesthesiology 45: 95-99. Link: https://goo.gl/nLh5SU

12. Parkinson SK, Mueller JB, Little WL, Bailey SL (2010) Extent of blockade with various approaches to the lumbar plexus. Anesth Analg 68: 243-248.

13. Horasanli E, Gamli M, Pala Y, Erol M, Sahin F, et al. (2010) A comparison of epidural anesthesia and lumbar plexus-sciatic nerve blocks for knee surgery. Clinics 65: 29-34. Link: https://goo.gl/DvTAq3

14. Petchara S, Paphon S, Vanlapa A, Boontikar P, Disya K (2015) Combined lumbar-sacral plexus block in high surgical risk geriatric patients undergoing early hip fracture surgery. Malaysian orthopaedic journal 9: 28-34. Link: https://goo.gl/Z6DNDC

15. Greengrass RA, Klein SM, D'Ercole FJ, Gleason DG, Shimer CL, et al. (1998) Lumbar plexusand sciatic nerve block for knee arthroplasty: comparison of ropivacaine and bupivacaine. Canadian journal of anaesthesia 45: 1094 Link: https://goo.gl/6zdiQw

16. Gamli M, Sacan O, Baskan S, Ozciftci S, Gogus N (2011) Combined lumbar plexus and sciatic nerve block for hip fracture surgery in a patient with severe aortic stenosis. Journal of anesthesia 25: 784-785. Link: https://goo.gl/pKhF9q

17. Grant CRK, Checketts MR (2008) Analgesia for primary hip and knee arthroplasty: the role of regional anaesthesia. Continuing Education in Anaesthesia, Critical Care \& Pain 8: 56-61. Link: https://goo.gl/zp2cx8

Copyright: (c) 2019 Aravind kumar E, et al. This is an open-access article distributed under the terms of the Creative Commons Attribution License, which permits unrestricted use, distribution, and reproduction in any medium, provided the original author and source are credited 